\title{
Measurement of water turbidity "micro plankton" for Tigris river in Tikrit by laser
}

\author{
Faleh L. Mater ${ }^{1}$, Ahmad. M. Obaid Khedhair ${ }^{1}$ \\ ${ }^{1}$ Dept. of physics college of sciences Uni. Of Tikrit
}

Rec. 12 Sep, 2011 Accept. 3 Oct, 2011

\begin{abstract}
:
In this work we took three samples from the flowing Tigris River in Salahuddin - Iraq. Through this research was obtained two benefits, first determine the amount of attenuation by a helium neon laser, and the second measurement of the concentration of plankton in the flowing Tigris River by the measured unit mass regions. Results showed that the. Al-fat ha sample that was tested based on this scheme has been found that the amount of micro plankton river which is equal to $(0.5) \mathrm{gm}$ per $(500) \mathrm{ml}$ when the permeative intensity is equal to (32) lux. $\mathrm{m} 2$ and this is shown in figure (4), while in figure (5) appeared the proportion of river micro plankton in Tikrit sample (0.59) gm per (500) $\mathrm{ml}$ when the permeative intensity (29) lux.m2 and this difference in intensity between the two samples is due to logical reasons, The first reason is due to the location of each of the two samples, since Al-fat,ha is located in the northern city of Tikrit, is higher than the city of Tikrit above sea level, so the arable land remnants besides micro plankton river drift toward the city of Tikrit, and the second reason is the remnants of human population of Tikrit city.
\end{abstract}

Key words: Water turbidity, Micro Plankton, Attenuation coefficients. helium neon laser (He-Ne laser)

\section{Introduction: \\ Water Pollution Quality:}

Turbidity is a measure of the cloudiness of water. It is used to indicate water quality and filtration effectiveness. The unit of turbidity is NTU.

Turbidity is caused by erosion runoff and discharges. It mainly has to do with measuring the light shining through a container holding water. (Al- Dienee, 2005).

Turbidity of water is often caused by the presence of suspended and dissolved matter such as dirt, clay, silt, finely divided organic matter and this call (micro plankton). Turbidity measurement is a qualitative parameter for water but its traceability to a primary standard allows the measurement to be applied as a quantitative measurement. (Mike Sadar, 2004).

\section{Common Turbidity Technologies:}

The vast number of different technologies can be categorized by three different variables. One variable is the type of incident light source that is used. The second variable is the detection angle for the scattered light. The third variable is the application of multiple detectors, a technique known as rationing. (Mike Sadar, 2004).

\section{Types of photon interaction:}

Photons may undergo various possible interactions with the atoms of an attenuator; the probability or cross-section for each interaction depends on the energy $(h \mathrm{n})$ of the photon and on the atomic number $Z$ of the attenuator, The photon interactions may be with a tightly bound electron with the field of the nucleus (pair production) or with an essentially free orbital electron (Compton effect, triplet production), In the context of photon interactions, a tightly bound electron is an orbital electron with a binding energy of the order of, or slightly larger than, the photon energy, while a free electron is an electron with a binding energy that is much smaller than the photon energy, During the interaction the photon may completely disappear (photoelectric effect, pair production, triplet production) or it may be scattered coherently (coherent scattering) or incoherently (Compton effect). (E.B. Podgorsak, 2005).

\section{Attenuation coefficients:}

The interactions between radiation and matter. Here radiation is defined broadly to include charged particles such as alpha and beta radiation, beams of charged particles created by accelerating machines as well as 
electromagnetic radiation or photons. When a beam of radiation of any kind penetrates matter some of the radiation may be absorbed completely, some may be scattered and some may pass straight through without any interaction at all. The processes of absorption and scattering can be described and explained in terms of interactions between particles.

If the interactions are of attenuation of a beam of articles with identical energies, all traveling in the same direction, is described by an exponential law. If at some distance into the material $\mathrm{N}_{0}$ particles are moving through a slab of material, then after penetrating an extra distance $\mathrm{x}$ it is found that the number of particles in the beam is reduced to

$\mathrm{N}(\mathrm{x}) \square=\mathrm{N}_{0} \mathrm{e}^{-\alpha \mathrm{x}}$

This exponential attenuation law follows from the fact that, over any short distance, the probability of losing a particle from the beam is proportional to the number of particles left. (G.F. Brand, 1992).

\section{The Laser:}

A laser is a device that amplifies light and produces a highly directional, highintensity beam that most often has a very pure frequency or wavelength. The word laser is an acronym for Light Amplification by Stimulated Emission of Radiation. (William, 2004).

\section{He-Ne LASERS:}

The He-Ne laser has long been the most common gas laser. It was also the first gas laser and the first c.w. (continuous waves) laser. The first $\mathrm{He}-\mathrm{Ne}$ emitted in the near infrared at $1,152 \mathrm{~nm}$. The familiar red line at $632.8 \mathrm{~nm}$ was discovered later and is not as strong-but it became extremely important because it's easily visible to the human eye. He-Ne lasers emitting a few milliwatts were the first lasers to be mass produced and found wide use in applications from supermarket scanners to surveying equipment. (Breck Hitz, 2001).

\section{Types of Optical Detectors:}

Optical detectors are usually divided into two broad classes: photon detectors and thermal detectors. In photon detectors, quanta of light energy interact with electrons in the detector material and generate free electrons. To produce free electrons, the quanta must have sufficient energy to free an electron from its atomic binding forces. We are here used the lux meter detector. (Chandrasekhar Roychoudhuri, 2008).

\section{The Lux Meter detector:}

A lux meter is a device for measuring brightness. It specifically measures the intensity with which the brightness appears to the human eye. This is different than measurements of the actual light energy produced by or reflected from an object or light source. The lux is a unit of measurement of brightness, or more accurately, illuminance. It ultimately derives from the candela, the standard unit of measurement for the power of light. A candela is a fixed amount, roughly equivalent to the brightness of one candle. (2003).

\section{The practical part: \\ Used tools:}

Helium - neon laser, lux meter, beaker, clean water, river dirt, lens

\section{The Stage of collect and prepare samples:}

- at the beginning three samples had taken from Tigris river that pass from Salahuddin governorate, the first sample had taken from unlimited place from Tigris river then the water had filter from micro plankton by two stage, after that , the sample has leaves for one day where the purpose for recession the micro plankton.

- at the second stage, the refined water sample was filtered by filter paper to refine what still from the micro plankton. the purpose from this stage is to obtain a pure water sample, which can be consider as a standard sample to Tigris river, as a result we can establish standard diagrams that help to detect the ratios of pollution of micro plankton of Tigris river as will explain it later.

- the second sample had taken from al-fat' ha area that closes by thermal station in al- Baige region because of two reason, the first it placed near to electric power generator station and the middle to the border to Salahuddin and Kirkuk governorate.

- this excellent position gives a good conception about the amount of water pollution at the limited place. 
- the third sample had taken from Tikrit city, the center of Salahuddin governorate.

\begin{tabular}{|c|c|c|}
\hline $\begin{array}{c}\text { Attenuatio } \\
\text { n ratio }\end{array}$ & $\begin{array}{c}\text { Ratio of } \\
\text { micro } \\
\text { plankton } \\
\text { (gm / half } \\
\text { litter) }\end{array}$ & $\begin{array}{c}\text { Intensity of } \\
\text { permeative } \\
\text { light } \\
\text { (lux.m } \mathbf{2}^{\mathbf{2}}\end{array}$ \\
\hline 0 & 0 & 47 \\
\hline 0.038 & 0.5 & 32 \\
\hline 01140. & 1 & 15 \\
\hline 0.177 & 1.5 & 8 \\
\hline 0.246 & 2 & 4 \\
\hline
\end{tabular}

Table (1) the relation between ratio of river micro plankton and Intensity of permeative light

The stage of testing and measuring

after getting on the first pure sample had been beginning to establish a standard diagram that can be credit to detect the pollution of micro plankton in the Tigris river and according to the following steps :-

- a band of laser beam light He-Ne laser type with (632.8) $\mathrm{nm}$ wavelength and with $(1 \mathrm{~m} \mathrm{~W})$ power upon the pure water sample to know the permeative intensity value which it express about not existence of any micro plankton in the sample.

- had been taken micro plankton fron Tigris river then added a limited and increased amounts with constant value from it add to the sample, and after every adding we measured abound of laser beam light on the sample to learn the permeative intensity (that decreasing with all adding) and which it express about of the addition micro plankton amount.

- After every test the value of the occurring attenuation has been calculate on the laser band, and at the end the results is coming identical to Lambert low and it which demonstrate an increase in the permeative intensity attenuation as a function of increase in the micro plankton value that adding in the medium.

- At last had been get on a standard diagram can be from it to detect about of micro plankton concentration as a function of the permeative for the attenuation value, as can be sensing the attenuation value and the permeative intensity. for the two samples that had taken from al-fat'ha and Tikrit regions its easy to know the micro plankton which find in their water according to the standard diagram ,if had been pass a band of $\mathrm{He}-\mathrm{Ne}$ laser that using on the two samples (after mixing process each sample alone) it will detect after that about of the value of micro plankton concentration ratio in each sample by lux meter device which used to receive the permeative intensity.

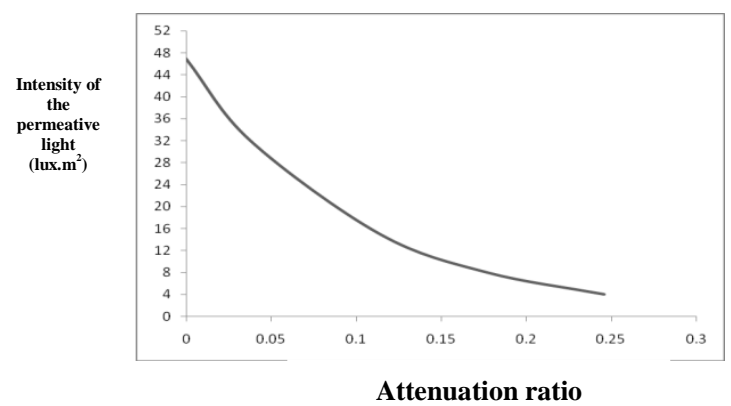

Figure 3. a standard model shown the relationship between the intensity of the permeative light. and the attenuation ratio.

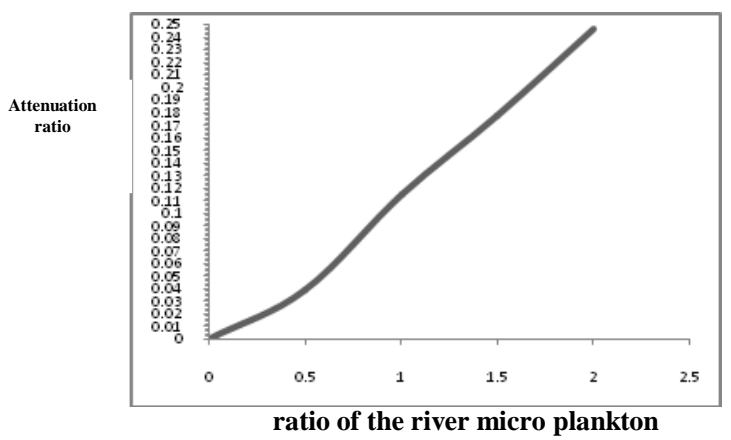

Figure 2. a standard model shown the relationship between the attenuation ratio and ratio of the river micro plankton .

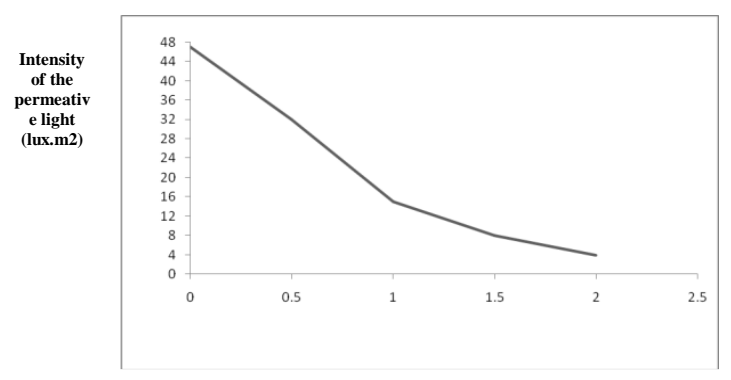

Ratio of the river micro plankton (gm / 500mil)

Figure 3. a standard model shown the relationship between the Intensity of the permeative light and the ratio of the river micro plankton 


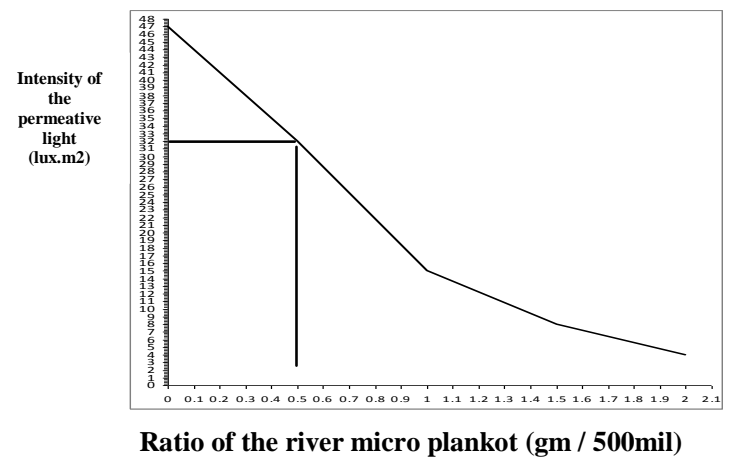

Figure 4. the ratio of dirt effecting on permeative light in the river Of Al-fat ha area

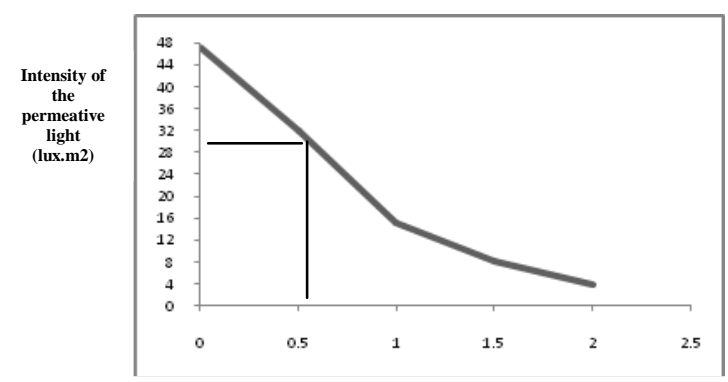

Ratio of the river micro plankton (gm/ 500mil)

Figure 5. the ratio of micro plankton effecting on permeative light in the river Of Tikrit city

\section{Results and discussion:}

From Table (1), which represents the standard value can be relied upon to calculate the rates of pollution by river plankton and clays. Can also be useful in this table will be possible to detect in the standard form. Table (1) column shows the permeative intensity through the standard samples, and this intensity is a function of micro plankton river and arable land and also a function of the attenuation ratios in the original intensity, and as is apparent in the shapes subsequent. Note from the table (1) that the rates of micro plankton and river clays that have been added and is an increasing will reduce the permeative intensity and this is what is noted in the figures $(1,2)$ explained the relationship with each of the intensity of the permeative light attenuation coefficient and the percentages of river micro plankton, as for figure (3) showed linear relationship between each of the intensity of permeative light and ratio of river micro plankton. As can be seen from the table (1) mentioned above, that the values of intensity is inversely proportional to the increase of the amounts fixed blocks of river plankton added, as the table indicate that the amount of the increase in river plankton was added by (0.5) gm at a time. Yet the figures (1,2 and 3) possible use in a broad spectrum blocks and the other hand, it will be for each value of the mass of micro plankton that appear within the river center river there will be a signal to the permeative intensity or the value of attenuation coefficient, which appear on the y-axis. Therefore, these figures can be considered a standard approved schemes in the detection rates of pollution in the Tigris river or other rivers. And also possible to expand the range of values on the $\mathrm{x}-\mathrm{y}$ axes as required by the study, and this is what will expand the use of these schemes in this field, Therefore, Al-fatha sample that was tested based on this scheme has been found that the amount of micro plankton river which is equal to $(0.5)$ per gram (500) $\mathrm{ml}$ when the permeative intensity is equal to (32) lux. $\mathrm{m}^{2}$ and this is shown in figure (4), while in figure (5) appeared the proportion of river micro plankton in Tikrit sample $(0.59) \mathrm{gm}$ per $(500) \mathrm{ml}$ when the permeative intensity (29) lux. $\mathrm{m}^{2}$ and this difference in intensity between the two samples is due to logical reasons, the first reason, The first reason is due to the location of each of the two samples, since Al-fatha is located in the northern city of Tikrit, is higher than the city of Tikrit above sea level, so the arable land remnants besides land and micro plankton river drift toward the city of Tikrit, and the second reason is the remnants of human population of the Tikrit city, the largest area of the hole because of low population density in Al-fatha.

\section{Conclusions:}

From the previous work it is can be to conclude the following:

1- The difference in the concentration of micro plankton river between the two regions is not large and the reason may be come back from convergent of the level of the two regions of throwing from human succeeded besides the difference in its descent of sea level is not big.

2- Succeeding this technique to detect the pollution of waters in the two regions besides to proving the magnitude of the real difference between the pollution concentration for the two regions.

\section{References:}

Al-Dienee Nadia Mohammed Jassim," Detection of Water Pollutants By 
Means of Laser Technique" A Thesis Submitted to the Institute of Laser for Postgraduate Studies University of Baghdad As a Partial Fulfillment of the Requirements for the Degree of Master of Science in Laser / Physics, (2005).

Mike Sadar" Instrumentation and best practice techniques Are key to effectively monitor turbidity in Natural water bodies",

Turbidity Measurement: A Simple, Effective Indicator of Water Quality Change, (2004).

Mike Sadar "Making Sense of Turbidity Measurements - dvantages In Establishing Traceability Between Measurements and Technology" Hach Company, 5600 Lindbergh Drive, Loveland, Colorado 805390389, (2004).
E.B. Podgorsak "Radiation Oncology Physics" A Handbook for Teachers and Students. Technical Editor, (2005).

G.F. Brand, I.S. Falconer, M.I. arge I.M. Sefton, J. Ulrichs, G.C. Vorlicek M.M. Winn "Atoms and Nuclei " Third ed., (1992).

William T.silfvast "laser fundamentals", second edition, (2004).

Breck Hitz, J.J. Ewing and JEFF HECHT "introduction to laser technology" Third Edition, (2001).

Chandrasekhar Roychoudhuri "Fundamentals of Photonics, Optical Detectors and Human Vision" Consultant, formerly with Honeywell Technology Center Edina, Minnesota, (2008).

What is a lux meter? http://www.wisegeek.com/what-is-alux-meter.htm, (2003).

\section{قياس عكورة المياه ( العوالق المجهرية الاقيقة ) لنهر دجلة في تكريت باستخدام أشعة الليزر}

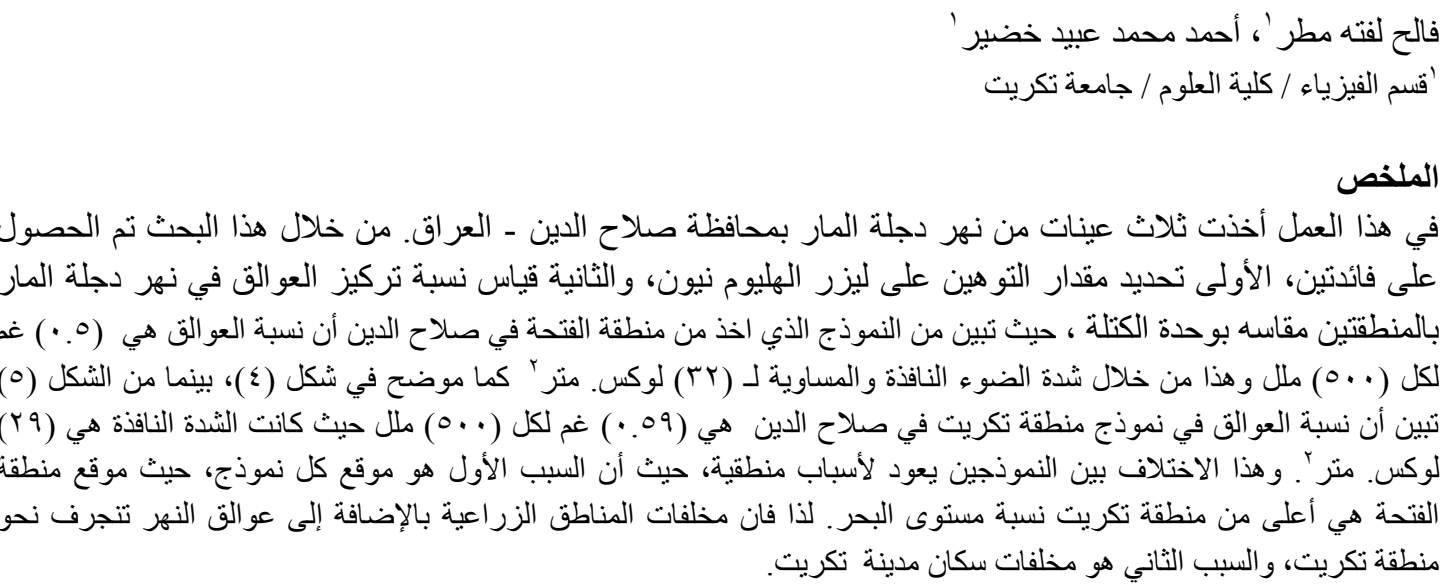

